\title{
DISCUSSION
}

\section{Fall-cone penetration and water content relationships of clays}

\author{
T. W. FENG (2000). Géotechnique 50, No. 2, 181-187
}

P. J. Brown and M. C. Downing, Southampton Institute, UK

The author suggests a more controllable procedure for determining the plastic limit of fine-grained soils using a standard fall cone. Although the current thread-rolling method is categorised as a simple index test, this belies its underlying complexity. Its subjective nature and susceptability to operator judgement are two well-documented drawbacks. However, its attractiveness lies in the fact that it is a reasonably rapid test to perform.

The author describes a method of sample preparation that may require expertise on a par with the current thread-rolling method. Preparing a homogeneous paste with a uniform equilibrium moisture content by air drying requires some care, particularly down to the levels required to achieve $3-4 \mathrm{~mm}$ penetration of a standard $80 \mathrm{~g}$ cone. This perhaps takes the method out of the realms of being a simple index test.

Although the author describes the use of 'mounding' and cutting rings as opposed to cups, it is unclear how this would reduce the presence of trapped air.

A comparison between two sample preparation methods in the cone penetration range of $15-25 \mathrm{~mm}$ (i.e. at liquid limit consistencies) shows little difference in liquid limit values obtained (Brown \& Downing, in prep.). In the standard test the specimen cup was filled as per the method in BS 1377: Part 2: 1990. In the 'compacted' test the cup was quarter filled with soil paste, taking care not to entrap air. The cup and sample were then tapped sharply and squarely on a concrete plinth 10 times. The procedure was repeated another three times, the final layer being slightly overfilled and excess paste struck off with a blade.

Twenty-six samples of natural UK soils ranging from CL to CE were tested, and corresponding liquid limits varied from 24 to 90 , as determined by the cone penetrometer method. The comparative results are shown in Fig. 1. Corresponding mean and standard deviation values were quite comparable. The mean result for liquid limit was 48 for both compacted and standard preparation methods with standard deviations of 18.3 and 18.2 respectively.

It is suggested that an effect more important than any loading/unloading of the sample (whether by pushing the sample into the test cup or by 'mounding') is particle crushing. This can take place during mixing to a uniform equilibrium moisture content.

The assumption in the Feng method that there is a hundredfold increase in shear strength from liquid limit to plastic limit state is, as Feng acknowledges, a likely source of error. Data on 147 samples of natural UK soils show the measured ratio to vary between 15 and 397 with a mean in the region of 140 (Brown and Downing, (in prep.)).

Consideration of published data shows a similar range of strength values at the plastic limit (Skempton \& Northey, 1953; Arrowsmith, 1978; Dennehy, 1978; Wasti \& Bezirci, 1986; Brown \& Huxley, 1996). One of the reasons for this reported wide range is probably the very empirical nature of the thread rolling test.

Another likely source of error is in the assumption that cone factor, $k$ (as defined by Hansbo, 1957), is constant over the plastic range. Brown \& Huxley (1996) show that, while it can be considered constant at cone penetrations associated with the liquid limit test, this is clearly not the case at lower penetrations and hence moisture contents near the plastic limit.

Data for a single $30^{\circ}$ cone and single operator give $k=0.81$ in the region of the liquid limit and 0.26 at the plastic limit. (Brown and Downing, in prep.). It is convenient to present these data in the form of cone mass, $W$, divided by penetration squared, $d^{2}$, plotted against shear strength, $C_{\mathrm{u}}$ (Fig. 2). This is derived from Hansbo's equation:

$$
k=\left(C_{\mathrm{u}} \cdot d^{2}\right) / W
$$

The same data can be used to assess the Feng relationship using



Fig. 1. $w_{\mathrm{L}}$ (BS come method) plotted against $w_{\mathrm{L}}$ (compacted) 


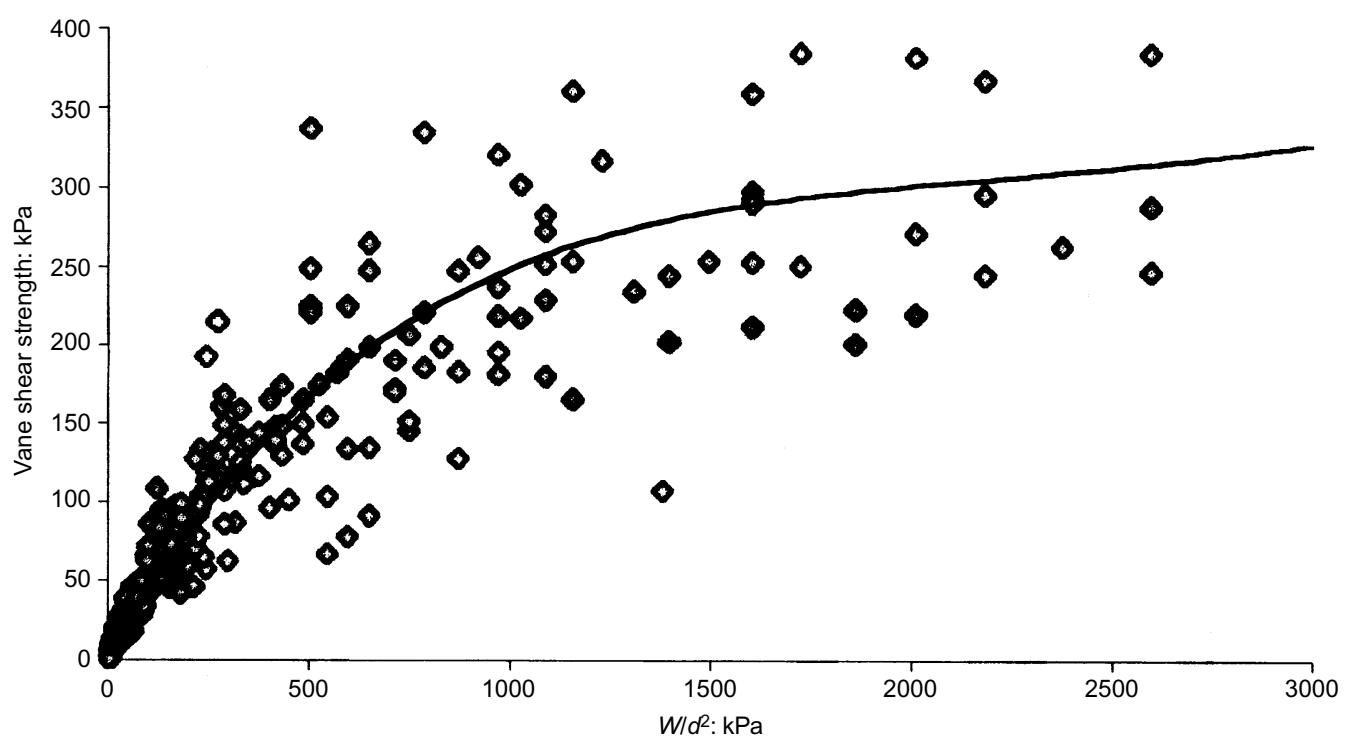

Fig. 2. Cone factor

all cone penetration points (between 10 and 18 per sample tested; Fig. 3), and four points between $3 \mathrm{~mm}$ and $25 \mathrm{~mm}$ cone penetration (Fig. 4; Brown and Downing, in prep.).

Although correlation factors are reasonable at 0.7582 and 0.8124 it is suggested that the Feng method may not commercially replace the current plastic limit test. This is due to the considerable expertise needed in sample preparation and the time delay involved in air drying to consistencies required for penetrations of 3-4 $\mathrm{mm}$, particularly in high plasticity soils.

Based on the data from Brown and Downing (in prep.), it is agreed that the Harison relationship does not appear to give a good prediction of plastic limit, although a constant underestimation is not suggested.

\section{Author's reply}

There is no doubt that the thread-rolling method is simple, but it has long been criticised for involving considerable operator judgements. There is a need for a simple and reliable test to replace the thread-rolling method.

The author appreciates the comments by the discussors, but does not agree with many of them. Firstly, for 3-4 $\mathrm{mm}$ of penetration, a small cutting ring $10 \mathrm{~mm}$ in diameter and $10 \mathrm{~mm}$ in depth can be used to hold the specimen. This means that only about $1 \mathrm{~cm}^{3}$ of soil paste is required. In this case, the water content of the soil paste can be reduced quickly to near the plastic limit in the same way as that used in the threadrolling method. It is also simple then to push the small cutting ring downwards into the soil paste to obtain a specimen for the fall cone test. It is the author's experience that it takes only minimal practice for a motivated civil engineering student to master the fall cone plastic limit test. These factors, taken together, make the fall cone test a simple and reliable test for determining the plastic limit. Incidentally, an example of four penetrations evenly distributed between $25 \mathrm{~mm}$ and $3 \mathrm{~mm}$ for determining the $\log -\log$ relationship may be $23 \mathrm{~mm}, 17 \mathrm{~mm}$, $11 \mathrm{~mm}$ and $5 \mathrm{~mm}$. The specimen preparation for penetration of around $5 \mathrm{~mm}$ is less difficult than that for penetration of $3-$ $4 \mathrm{~mm}$.

The BS fall cone method recommends filling the specimen cup with a portion of the mixed soil paste. As the portion of soil paste generally has irregular shapes and variable sizes, the author has found that avoiding trapping air during the filling process is rather tedious. On the other hand, the cutting ring is open at both ends, and the soil mound is prepared to have a diameter larger than the cutting ring, which can completely avoid trapping air in the specimen by pushing the cutting ring

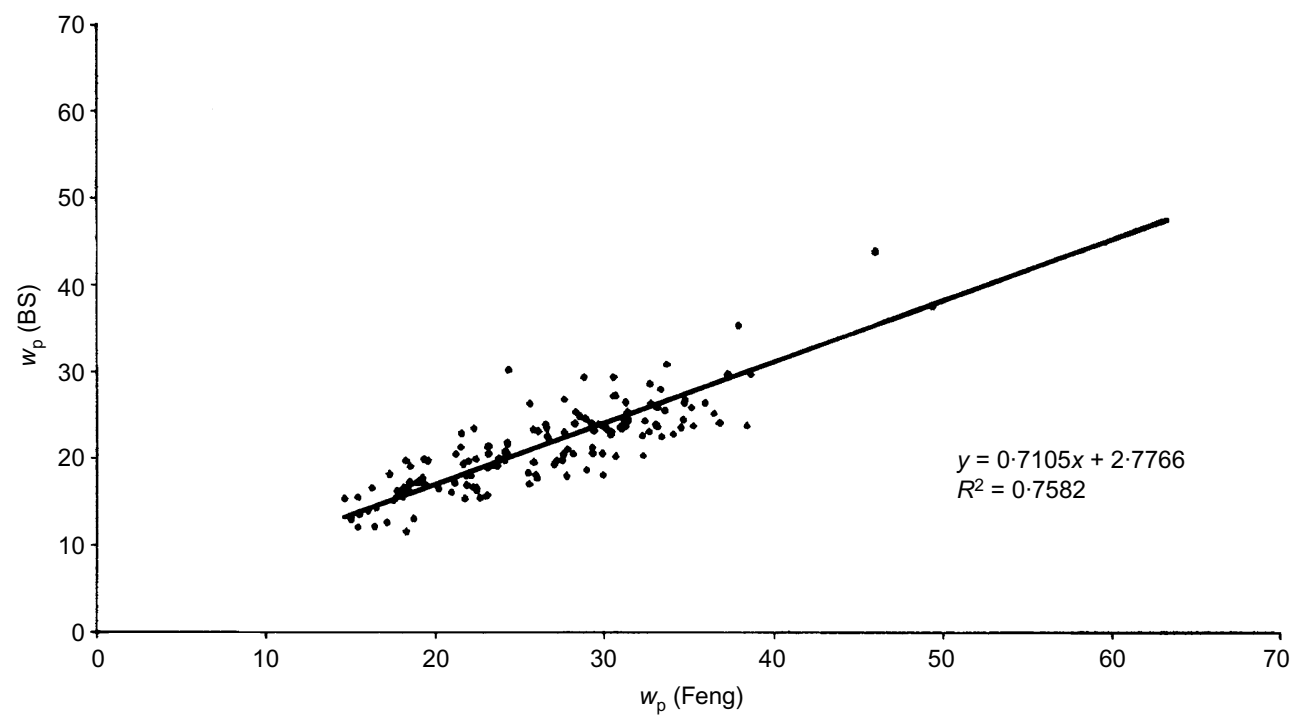

Fig. 3. $w_{\mathrm{p}}$ (Feng) plotted against $w_{\mathrm{p}}$ (BS), all penetration points, 147 samples 


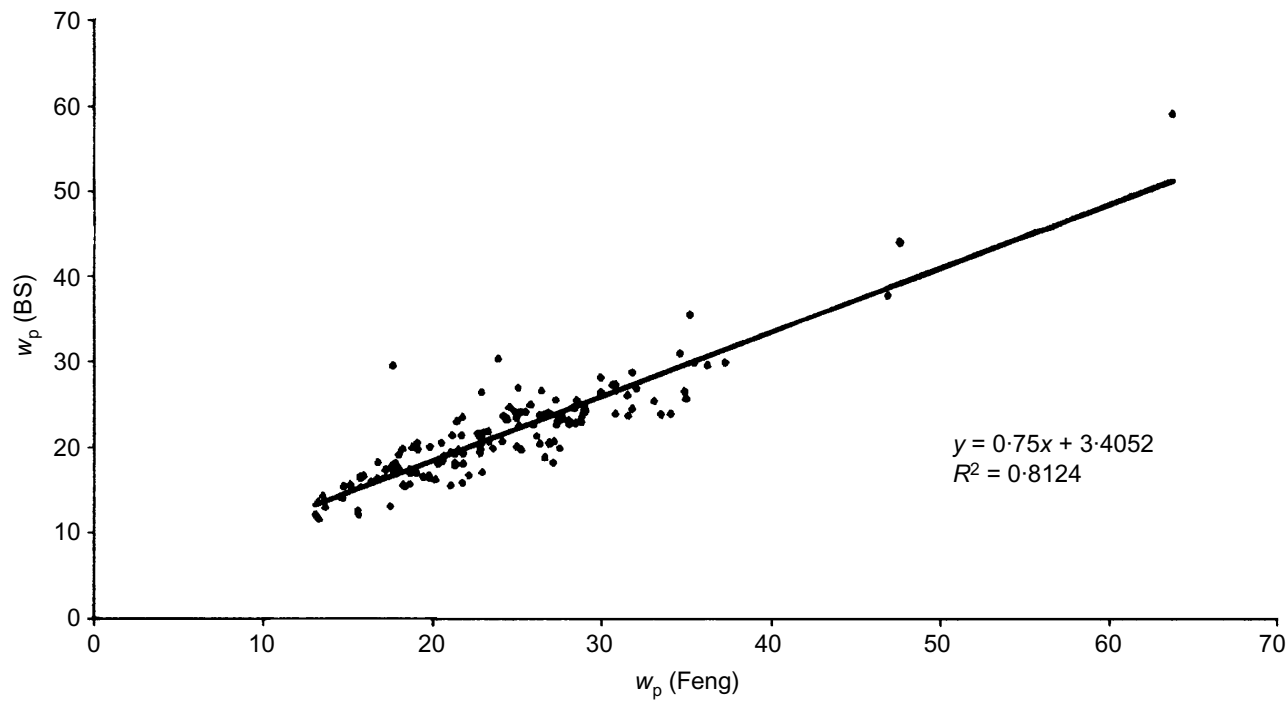

Fig. 4. $w_{\mathrm{p}}$ Feng plotted against $w_{\mathrm{p}}$ BS, four penetration points $3-25 \mathrm{~mm}, 147$ samples

downwards into the soil mound. Although the discussors' 'compacted' test is believed to be also an effective method to reduce the presence of trapped air, it is apparently time consuming, and its effectiveness is expected to reduce rapidly with decreasing water content especially for water contents near the plastic limit.

The data shown in Fig. 1 are liquid limits of 26 soils: therefore it is meaningless to compute and compare their mean and standard deviation values. The $R^{2}$ value being equal to 0.9866 is sufficient to show a good correlation between the two sets of liquid limit values.

It is difficult to visualise how silt particles and clay particles would crush during mixing of the soil sample.

It is generally known that the vane shear apparatus is used to measure the undrained strength of 'soft clays'. But the discussors have reported vane strength values as high as $400 \mathrm{kPa}$ with large scatters, as shown in Fig. 2. It is highly questionable in using the vane apparatus to measure the undrained strength of stiff soils. Furthermore, Fig. 2 contains a majority of data points corresponding to fall-cone penetrations of less than $3 \mathrm{~mm}$. For instance, the $W / d^{2}$ value is equal to $89 \mathrm{kPa}$ for $3 \mathrm{~mm}$ of penetration. For the greatest reported $W / d^{2}$ value of about $2600 \mathrm{kPa}$, the corresponding penetration is $0.55 \mathrm{~mm}$, a very small value. The author agrees with the discussors view that it

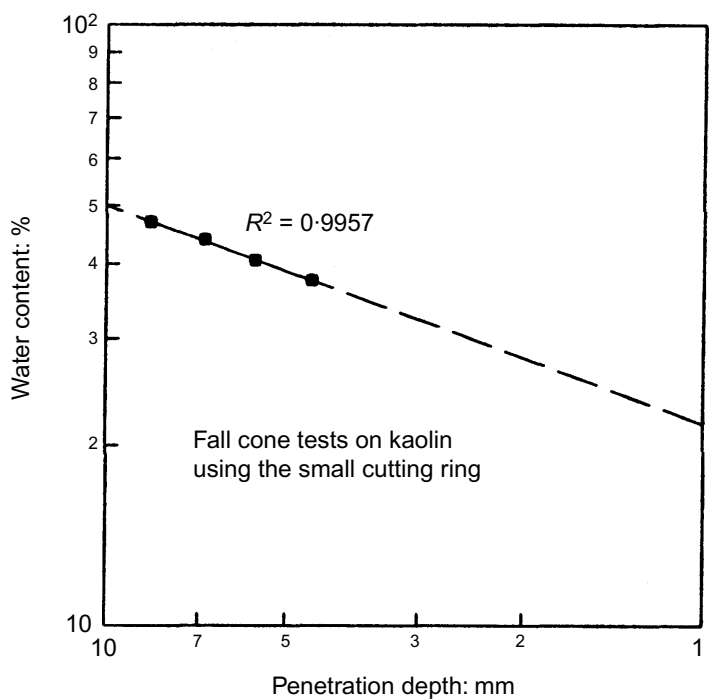

Fig. 5. Test results from the $30^{\circ}$ fall cone with the small cutting ring is difficult to use the liquid limit specimen cup $\left(95 \mathrm{~cm}^{3}\right.$ in volume) to prepare a soil specimen for 3-4 $\mathrm{mm}$ of penetration. The difficulty in specimen preparation is even more for penetrations less than $3 \mathrm{~mm}$. The data scatter and the variable cone factor, $k$, shown in Fig. 2, may be due largely to the problem with the thread-rolling method, the difficulty in specimen preparation with the cup for water contents toward the plastic limit, and the use of laboratory vane apparatus in stiff soils.

Recently, the author has made a small cutting ring of $20 \mathrm{~mm}$ in diameter and $20 \mathrm{~mm}$ in depth for penetrations between $12 \mathrm{~mm}$ and $3 \mathrm{~mm}$ using the $30^{\circ}$ fall cone apparatus. Only around $7 \mathrm{~cm}^{3}$ of soil sample is needed for a fall cone test with this ring. It is apparent from a number of the fall cone tests that specimen preparation with this ring does not require considerable expertise and can be carried out in a short time. Fig. 5 shows the data of four fall cone tests with this ring and the corresponding logarithmic penetration versus logarithmic water content relationship of a kaolin sample. The plastic limit estimated from this relationship is $27 \%$, whereas the plastic limit measured from the thread-rolling method is $26 \%$. This implies that the author's method may be considered to commercially replace the thread-rolling method.

\section{REFERENCES}

Arrowsmith, E. J. (1978). Roadwork fills: a material engineer's viewpoint. Proceedings Clay Fill Conference, pp. 25-36. London: Institution of Civil Engineers.

British Standards Institution (1990). BS 1377 British Standard methods of test for soils for civil engineering purposes. Part 2: Classification tests. London: BSI.

Brown, P. J. \& Downing, M. C. (in prep.). Fall cone and shear vane measurements of fine grained soils at their liquid limit and plastic limit consistencies.

Brown, P. J. \& Huxley, M. A. (1996). The cone factor for a $30^{\circ}$ cone. Ground Engng 29, No. 10, 34-36.

Dennehy, J. P. (1978). The remoulded undrained shear strength of cohesive solids and its influence on the stability of embankment fill. Proceedings Clay Fill Conference, pp. 87-94. London: Institution of Civil Engineers.

Hansbo, S. (1957). A new approach to the determination of the shear strength of clay by the fall cone test. Proc. R. Swedish Geotech. Inst., No. 14, 7-14.

Harison, J. A. (1988). Using the BS cone penetrometer for the determination of the plastic limit of soils. Géotechnique 38, No. 3, 433438.

Skempton, A. W. \& Northey, R. D. (1953). The sensitivity of clays. Géotechnique 20, No. 1, 30-53.

Wasti, Y. \& Bezirci, M. H. (1986). Determination of the consistency limits of soils by the fall cone test. Can. Geotech. J. 23, 241-246. 